\title{
DENTAL NURSES CATCH UP ONLINE WITH BADN
}

The British Association of Dental Nurses (BADN) is continuing with its highly successful monthly 'Coffee Catch Ups' for dental nurses.

Held on the last Saturday of every month at $3 \mathrm{pm}$, the Catch Ups are designed to give dental nurses a chance to network, chat with and ask questions of BADN President Jacqui Elsden, Executive Committee members and staff, and to be kept up to date with new developments. The Catch Ups also offer 30 minutes of verifiable CPD.

October's speaker was Jennifer da Silva of Parliament Hill, providers of 'BADN Rewards', BADN's membership benefits scheme. Jennifer outlined the benefits available to BADN members under the scheme and explained how to make best use of them.

November's speaker was Sharon Brennan, of CFC Underwriters, providers of BADN's indemnity scheme, who explained what indemnity actually is (medical malpractice and legal expenses cover), why dental nurses need it, the difference between insurance cover and discretionary cover, why so-called 'crown indemnity' isn't enough and current market conditions.

The December Catch Up - on the last Saturday before Christmas - featured motivational speaker and teambuilding guru Tracy Stuart. Tracy is highly respected as a successful Dental Business Coach \& Dental Team Trainer within the UK dental profession. The sole purpose of her company, NBS Training, is to mentor and coach dental practice owners and their dental teams.

Attendees at the December Catch Up were invited to wear a Christmas jumper or outfit, with a prize for the best ensemble.

The Catch Up events are open to all dental nurses and are free of charge; however, places are limited. A wide ranging programme is planned for 2021. For more information and to book a place, go to www.badn.org.uk or contact events@badn. org.uk.

\section{Dental Shouvcase moves online for 2021}

The BDIA Dental Showcase Advisory Board and MA Exhibitions Limited have taken the decision to reschedule BDIA

Dental Showcase to

25-26 March 2022 at ExCeL, London. For 2021, a brand new virtual event will take place on 22-26 March 2021: BDIA Dental Showcase On Demand.

For more information and to register your interest in the virtual event, visit https://ondemand. dentalshowcase. com/.

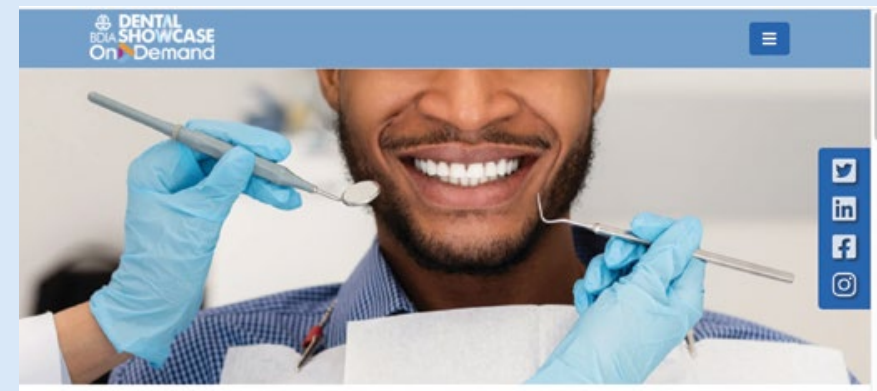

\section{WELCOME TO BDIA DENTAL SHOWCASE ON DEMAND 22-26 MARCH 2021 | THE NEW VIRTUAL EXPERIENCE}

It is more important now than ever to bring the dental profession and trade together.
New

\section{President} for BSIHT

The British Society of Dental Hygiene and Therapy (BSDHT) has announced that Diane Rochford is the new president of the Society.

Diane has proven herself to be a real asset to the Society during the last few years - not only steadfastly upholding its values but also joining in with its spirit of innovation and joining the campaign for change.

Previously, Diane held the position of Elected Council Member and acted as representative of the North West Regional group. Diane has also always been on the educational panel for the Society and has published many articles in the field.

Retiring president Julie Deverick has held the position for two years. The BSDHT thanked her and said: 'Julie has been fearless in promoting the voices of dental hygienists and dental therapists across the nation, not only by campaigning for change in the industry but also by offering a supportive shoulder for all those in need'.

The British Association of Dental Nurses (BADN) congratulated Diane on her appointment. BADN President Jacqui Elsden said: 'I look forward to working closely with [Diane] as Presidents of our respective associations' and wished Diane every success in her new role.

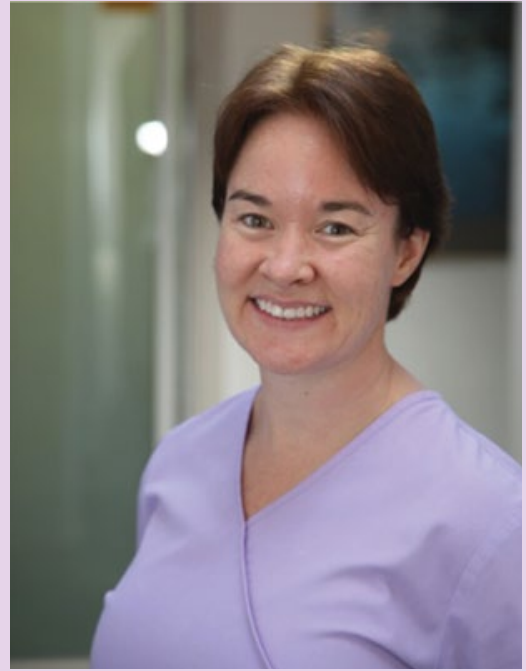

